\title{
Courtship duet between the female and the male Aedes aegypti queenslandensis (Theobald) (Diptera: Culicidae) under laboratory conditions
}

\author{
Elaisa Mae M. Jamora' ${ }^{1 *}$, Zaira Isabelle M. Gines' ${ }^{1}$ Claude Ceniza' ${ }^{2}$, Rommel G. \\ Bacabac $^{2}$ and Frances E. Edillo'
}

\begin{abstract}
This study aimed to determine the wing beat frequencies and spherical spreading between the female and the male Aedes aegypti queenslandensis during courtship under laboratory conditions. The field-collected larvae and pupae were reared into adult mosquitoes and were morphologically identified. Male and female individuals were coupled. Second generation of live adult mosquitoes were tethered to a stainless wire in their upright position and flight tones produced by their wings were recorded using pressure-gradient microphones. Results showed that the fundamental wing beat frequencies of male mosquitoes $(607-1,037 \mathrm{~Hz})$ were higher than those of the female $(487-660 \mathrm{~Hz})$. The different distances between male and female mosquitoes did not influence their wing beat frequencies $(p>0.05)$. Wing beat frequencies of male mosquitoes differed significantly when paired with the female, in all distances between them $(p<0.05)$, whereas those of females, did not differ $(p>0.05)$. Thus, the male Ae. aegypti queenslandensis adjusted and converged with the female's flight tone. Convergence was restricted to the fundamental frequency for all distances except at the 19-cm distance between them, where convergence happened in the harmonics. Analysis on the spherical spreading on their wing beat frequencies did not differ significantly $(p>0.05)$ in six locations of the microphones relative to the mosquitoes, thus, mosquitoes' flight tone moved in a spherical manner and that courtship could happen in different directions. Results are relevant for mosquito control by developing an acoustical device to disrupt their courtship.
\end{abstract}

Keywords: Aedes aegypti queenslandensis, dengue, wing beat frequency, spherical spreading, phase difference

'Department of Biology, University of San Carlos - Talamban Campus, Nasipit Talamban, Cebu City, 6000 Philippines

${ }^{2}$ Department of Physics, University of San Carlos - Talamban Campus, Nasipit Talamban, Cebu City, 6000 Philippines

\footnotetext{
* Corresponding Author. Address: Department of Biology, University of San Carlos - Talamban Campus, Nasipit Talamban, Cebu City,6000 Philippines; Email: jamoraella@gmail.com DOI: $10.32945 /$ atr 4022.2018
} 
Aedes aegypti (Linneaus) (Diptera: Culcidae) is the primary mosquito vector of dengue (DENV) and Zika (ZIKV) viruses. These flaviruses can be acquired from the blood of infected human and passed on to another human through an infected female Ae. aegypti (WHO 2015), although, ZIKV can also be transmitted sexually (WHO 2016). Among the ten Association of Southeast Asian Nations (ASEAN), Philippines ranked fourth in the number of dengue cases (Shepard et al 2013, WHOWPRO 2013). Dengue fever and Zika infections are on the rise (Benelli \& Mehlhorn 2016). Moreover, the recent tetravalent dengue vaccine (Dengvaxia) has an efficacy rate of only $56 \%$ for first time patient (Capeding et al 2014). Recently, the Philippine Department of Health (DOH 2017) received information from Sanofi Pasteur that Dengvaxia has shown consistent and sustained benefit for those who were previously infected with DENV. In the longer term, severe cases may occur following a subsequent dengue infection among those who were not previously infected.

Ae. aegypti queenslandensis (Theobald) is the very pale form and the most domestic of the three intraspecific forms of Ae. aegypti, breeds, and rests very close to humans, and co-occurs with the type form or Ae. aegypti sensu stricto (Mattingly 1957). Mattingly gave this form only a varietal rank (Ae. aegypti var. queenslandensis). Recently, Rasić et al (2016) reported that the queenslandensis and the type form are genomically indistinguishable implying that these forms freely interbreed at least in Australia and Singapore. Both sexes of Ae. aegypti in Cebu city, Philippines (Edillo et al 2015) and those of the pale and dark forms of Ae. aegypti in Bangkok, Thailand (Thungrungkiat et al 2012) showed natural vertical and transovarial transmissions of DENVs, respectively.

Female and male Ae. aegypti engage in acoustic manipulations as they encounter each other in mid-air that bring their flight tones (wing beat frequencies) in tune with each other (Cator et al 2009, Warren et al 2009). Their flight tone has their own unique type of vibration or standing wave pattern and are more than a mere byproduct of locomotion but are critical communication signals (Charlwood \& Jones 1979, Gopfert et al 1999). Moreover, flight tones produce a continuous sinusoidal tone at the frequency of wing movement, although higher harmonics (ie, the pattern produced with precise vibration frequencies and any frequency other than it results to an uneven, non-repeating medium disruption) may dominate in some insects (Sotavalta 1947, Williams \& Galambos 1950, Webb et al 1976). The relationship between two or more sound waves, when the mosquitoes meet in time and space, can be referred to as phase relationship. In-phase and outphase waves both have two waves with same frequency and are produced simultaneously and non-synonymously, respectively (Warren et al 2009, Wishart et al 1962, Tischner 1953, Tischner \& Schieff 1855, Belton 1974).

Long-standing questions remain about the sensory modalities and behavioral mechanisms that mediate mate finding and recognition. Thus, examining further the two-way communication between the male and the female Ae. aegypti queenslandensis may lead to discovering novel ways to control them and diseases they cause, particularly that there has been no study yet about this mosquito variety in the country. 
Courtship duet between the female and the male

\section{MATERIALS AND METHODS}

\section{Collection, rearing, and coupling of Ae. aegypti queenslandensis}

Ae. aegypti larvae and pupae were collected in Nasipit, Talamban, Cebu City, which had dengue cases (Cebu CHO 2016) and accessible to the researchers. Basins filled with mineral water and lined with filter papers at the side, which served as egg-laying substrates, were used to collect the mosquito eggs. Rearing of $A e$. aegypti subadults was modeled after Clemons et al (2010) and Edillo et al (2012), and was carried out inside the mosquito laboratory maintained at $23^{\circ} \mathrm{C}$ and $78 \pm 7 \%$ relative humidity (RH). Flakes of fish food (Sakura, All Aquarium Co Ltd Thailand) were used to feed the larvae (Figure 1). Newly emerged Ae. aegypti adults were allowed to become sexually mature for 3-4 days (Clemons et al 2010) and were sorted out morphologically by sex. Both male and female Ae. aegypti queenslandensis (see identification below) were placed in another coupling jar (Figure 2). Female mosquitoes were starved for a day and were fed by sucking the warm chicken blood placed inside an inverted microcentrifuge tubes covered with parafilm and were put on top of the fine mesh cloth. Female mosquitoes need blood to have the protein needed to synthesize the yolk and develop eggs for survival and reproduction (Nikbakhtzadeh et al 2016, Leal 2014). Meanwhile, cotton balls soaked in $10 \%$ sucrose solution were placed on top of each coupling jar to feed the male mosquitoes. A filter paper was placed at the bottom of the coupling jar for the collection of mosquito eggs. The first generation (F1)of Ae. aegypti queenslandensis eggs were obtained from the filter paper and were flushed with distilled water (DW) for hatching in another jar covered with fine-mesh cloth. Continuous rearing of mosquito subadults was done to ensure the supply of adult mosquitoes for the measurement of their wing beat frequencies.

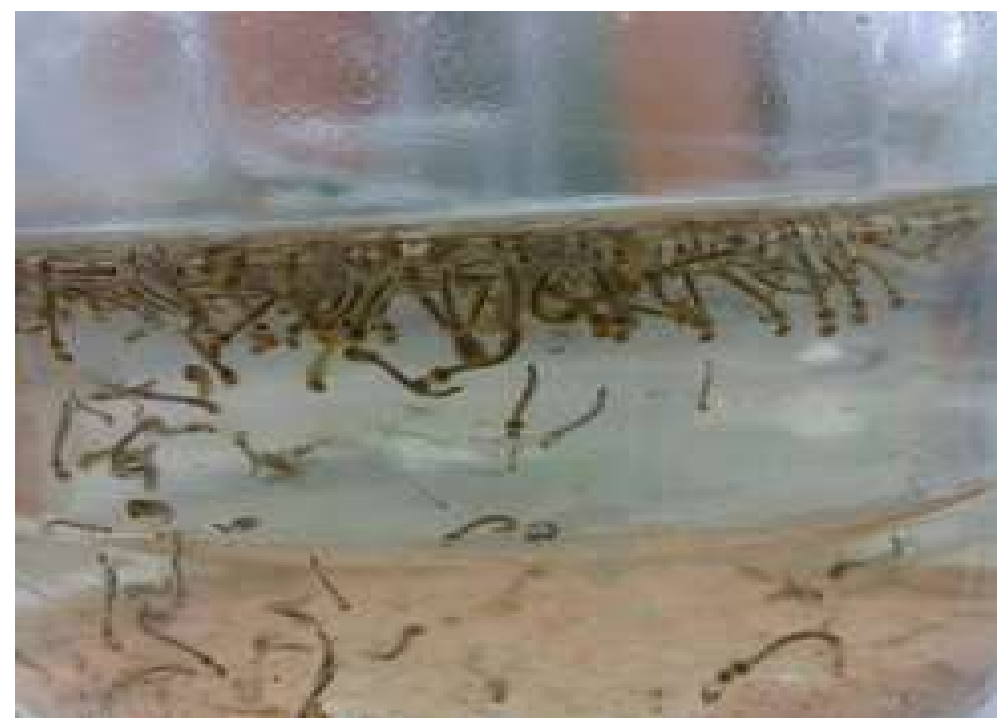

Figure 1. A glass jar with Aedes larvae being reared in the laboratory 


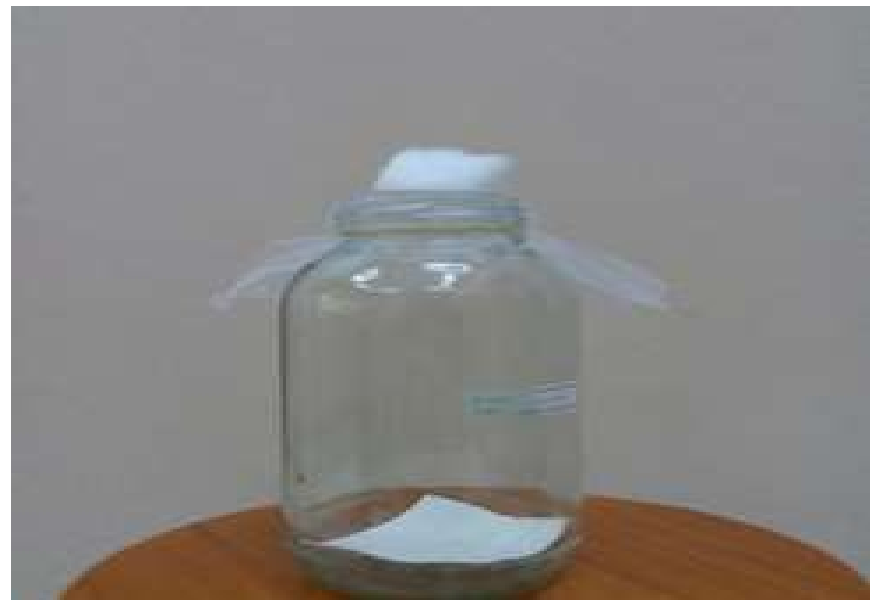

Figure 2. Coupling jar with a male and a female mosquitoes, a cotton ball on top soaked with $10 \%$ sucrose solution, and a filter paper that served as the substrate at the bottom for collection of mosquito eggs

\section{Identification of Ae. aegyptiqueenslandensis}

Newly emerged adults of Ae. aegypti were exposed inside the coupling jar with a cotton ball soaked with ethylene acetate for 10-15 sec. While the mosquitoes were still unconscious, they were placed under a dissectoscope for morphological identification following Mattingly (1957) and Kalra et al (1985). Male mosquitoes have a pair of more plumose antennae than those of females (Arthur et al 2014). Females are larger than male mosquitoes (Nicbakhtzadeh et al 2016). Briefly, Ae. aegypti queenslandensis has bleached dark scales, ranging from mid-brown to various shades of buff to almost white, found on the mesonotum as a distinct factor. Intrusion of pale, basal bands were also found on the abdominal tergite and on the tips of the succeeding segments (Figure $3 \mathrm{~A}$ ). Species identification was based on Thungrungkiat et al (2010) (Figure 3B-C).

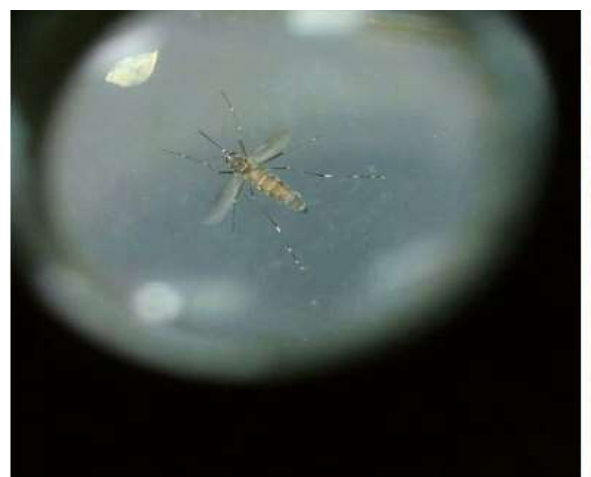

A

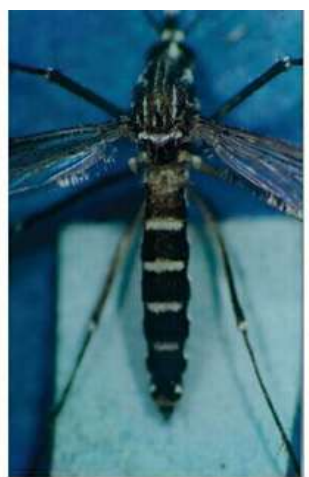

B

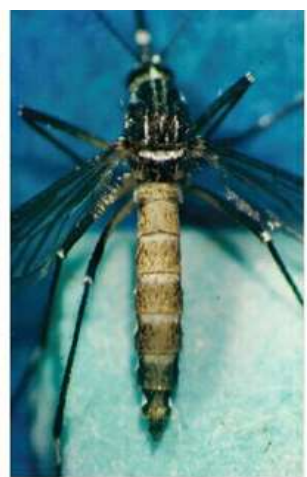

C

Figure 3A-C. Ae. aegypti queenslandensis in the current study (A); Ae. aegypti formosus (common form) (B) and Ae. aegyptiqueenslandensis (C) by Thungrungkiat et al (2010) 
Courtship duet between the female and the male

\section{Measurement of the Wing Beat Frequencies}

\subsection{Preparation of the microphones}

Measurement microphones of National Instruments Integrated Electronic Piezo Electric (NI-IEPE) (National Instruments Corporation, Austin, TX, USA) were used to capture the analog signal from the sound source. Calibration was performed in non-echoic laboratory conditions following Arthur et al (2010). In situ stimuli intensities were measured before recording sessions using NI-EPE measurement microphones. The microphone was positioned to where the mosquito was placed in parallel to the wave front coming from the distant speaker. To determine the sensitivity and dynamic range of the speaker, different tone frequencies and intensities were played, adjusted via a computer. Laboratory conditions were measured to check for changes in low-frequency sensitivity.

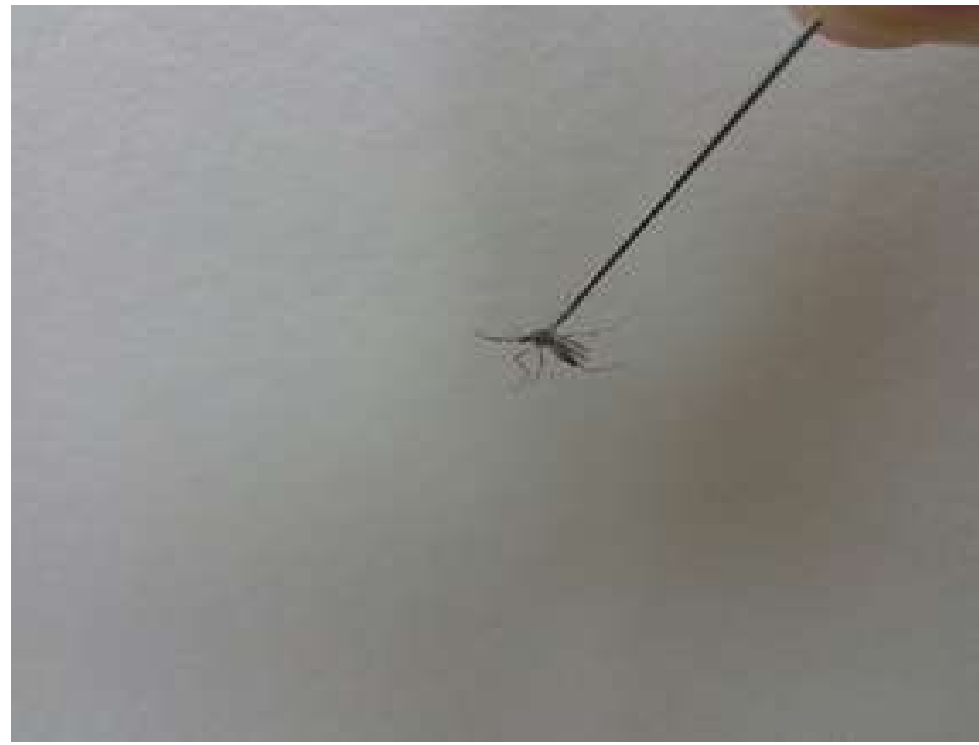

Figure 4. Tethered Ae. aegypti queenslandensis on its dorsal prothorax

\subsection{Wing beat frequencies}

Tethering mosquitoes in studying their flight kinematics is widespread. Consistent with Aldersley et al (2016), the simpler tethered experiments were performed because of the challenging nature of free flight experiments and at least some aspects of free flight behavior are preserved in tethered individuals. Each live mosquito (3- to 5-day old) was tethered on its dorsal prothorax with instant glue (Pioneer Mighty Bond, Philippines) to a stiff stainless wire (Figure 5); the latter was held for $5 \mathrm{sec}$ with the mosquito's upright flight position. It was allowed to acclimate by resting in a non-echoic laboratory for $\sim 5 \mathrm{~min}$. A pair of calibrated pressuregradient microphones was positioned on opposite sides of individual 
male ( $n=10$ per trial) and female mosquitoes ( $n=10$ per trial), simultaneously measuring the sound radiating from their wings in three successive trials. For the control group (Figure 5A), the wing beat frequencies of solo male and female mosquitoes were recorded with a $1-\mathrm{cm}$ distance from the microphone. For the duets (Figure 5B), the distances between a pair of male and female mosquitoes $(n=10$ pairs per trial) were varied $(1 \mathrm{~cm}, 7 \mathrm{~cm}, 13 \mathrm{~cm}$, and $19 \mathrm{~cm})$ (Arthur et al 2013), with three trials per distance.
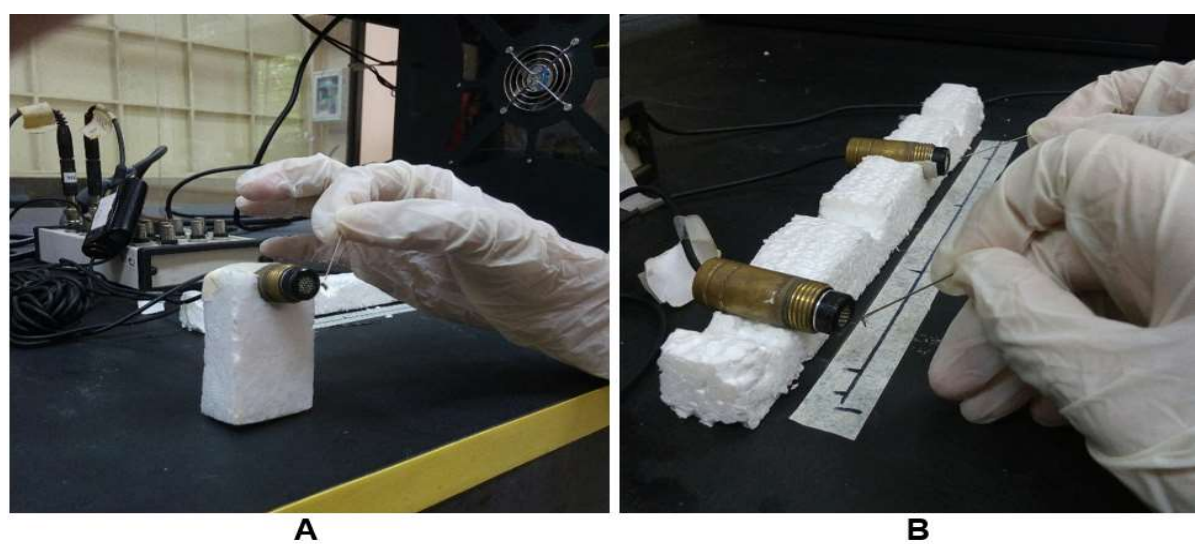

Figure 5A-B. Pressure-gradient microphones placed at a $1-\mathrm{cm}$ distance from the tethered mosquito (A) and at varied distances $(1 \mathrm{~cm}, 7 \mathrm{~cm}, 13 \mathrm{~cm}$, and $19 \mathrm{~cm})$ for the duet group (B)

\section{Analysis of Wing Beat Frequencies}

\subsection{Harmonicity and phase relationship}

Spectrograms were created using Fourier-transformed data on overlapped segments of time. Frequency modulation of its fundamental and harmonics were quantified using the estimated phase change that occurred in the Fourier coefficients if the time segment was shifted by one sample (Charpentier 1986, Brown \& Puckette 1993). Amplitudes of the fundamental and their harmonics at an instant in time were determined by averaging Fourier coefficients across a few successive segments that exhibited minimal frequency modulation, interpolating the magnitude spectrum at the set of integer-related frequencies closest to the peaks, and correcting with the microphone calibration data.

Decrease in amplitude with distance was adjusted with a power function, taking into account the 1-mm distance between the front of the microphone and the sensing diaphragm. Polyspectra were calculated on a line corresponding to the harmonic ratios of interest rather than over the full space (Brillinger 1965, Mendel 1991). Complex Fourier coefficients were conjugated as appropriate before plotting the logarithmic magnitude of their product (Kim \& Powers 1979).

\subsection{Spherical spreading}

Spherical spreading refers to the decrease of sound level generated by the mosquito as it propagates away from a source. From the center location of a 
Courtship duet between the female and the male

source, crests and troughs are established as spheres. This estimate expresses the uniformity of sound propagation in all directions. Six locations of the microphones relative to the mosquitoes were done, namely, (1) in front of their head, (2) behind the last abdominal tergite, (3) left wing, (4) right wing, (5) above, and (6) below in order for spherical spreading of their flight tones become evident. In each location, three trials were performed.

Between recordings, mosquito flight was inhibited by allowing it to grab on a piece of paper $(5 \mathrm{~cm} \times 5 \mathrm{~cm})$ and was initiated by removing the paper and when necessary, a gentle air puff was applied unto the mosquitoes. Data were acquired in a computer after digitizing (National Instrument USB Digitizer) by using custom software written in Laboratory Virtual Instrument Engineering Workbench (LabVIEW, National Instruments Corporation, Austin, TX, USA). A 10,000-Hz sample rate was permitted for $5 \mathrm{sec}$ of the flight tone for each trial.

\subsection{Statistical analysis}

Dependent variables (wing beat frequencies, harmonics, and phase relationships) of the above trials were analyzed by determining first the descriptive statistics. Student's T-test was used to determine whether there was a significant change between the mosquito's flight tones when in solo and in courtship. One-way analysis of variance (ANOVA) was used to determine whether distance affected the wing beat frequencies of the mosquitoes during courtship by using Minitab 17 statistical software (Pennsylvania, PA, USA).

\section{RESULTS AND DISCUSSION}

\section{Wing Beat Frequencies of Ae. aegypti queenslandensis}

\subsection{Single mosquitoes}

The male fundamental wing beat frequencies (range: $607-1,037 \mathrm{~Hz}$; mean: 824 $\pm 72 \mathrm{~Hz}$ ) of Ae. aegypti queenslandensis were higher than those of the female (range: $487-660 \mathrm{~Hz}$; mean: $570 \pm 39 \mathrm{~Hz}$ ) (Figure 6A-B). Both sexes differed in their wing beat frequencies significantly $(p=0.00)$.

Similar to the previous reports (Cator et al 2009, Gŏpfert et al 1999), tethered male Ae. aegypti fly at a higher fundamental frequency than female mosquitoes (691.2 Hz vs. $479.8 \mathrm{~Hz}$, respectively). Current results showed that the wing beat frequencies of tethered Ae. aegypti queenslandensis were slightly higher than those reported by Göpfert et al (1999) and Cator et al (2009). However, free flight of Ae. aegypti (Cator et al 2011) shows higher fundamental frequencies than in this study ( $982 \mathrm{~Hz}$ vs. $824 \mathrm{~Hz}$ for males; $664 \mathrm{~Hz}$ vs. $570 \mathrm{~Hz}$ for females, respectively). Evidences showed that tethering results in a decrease in mosquito wing beat frequency compared with free flight (Arthur et al 2014, Cator et al 2009, Cator et al 2011). 
Jamora et al

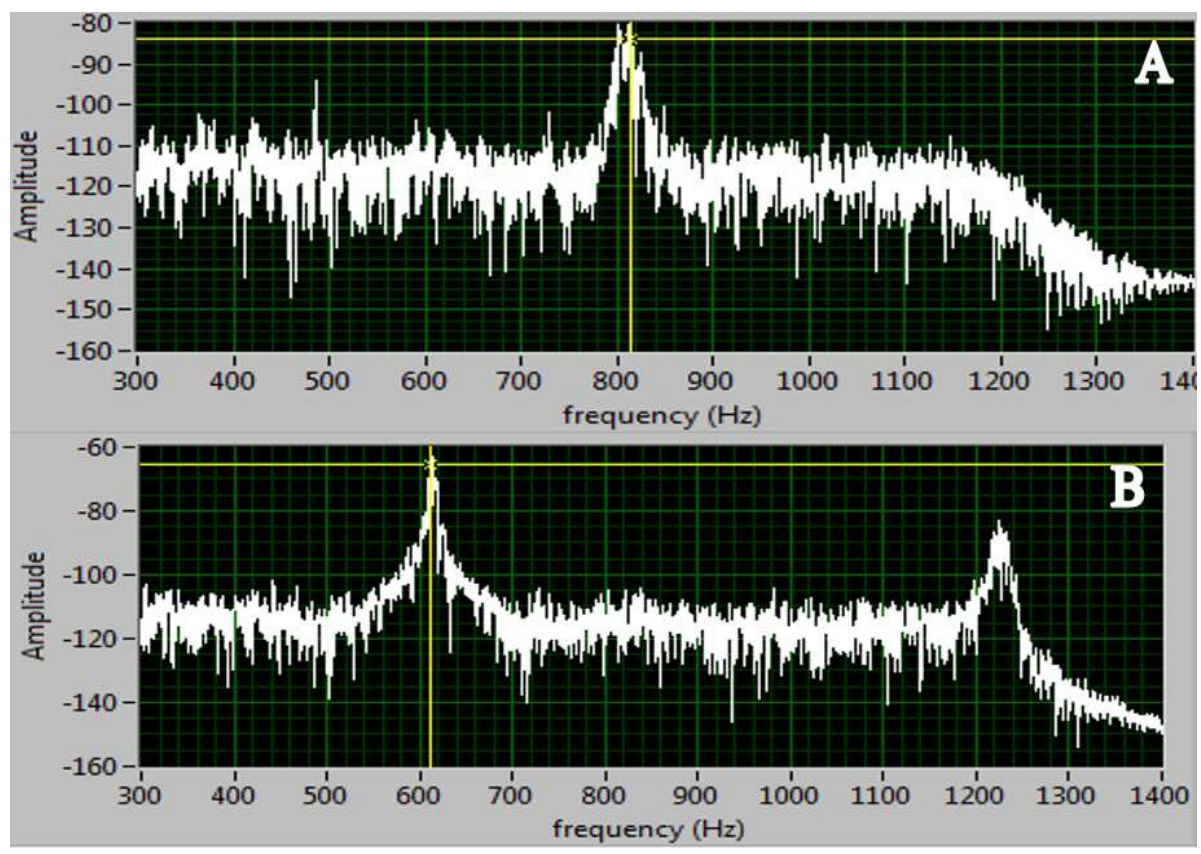

Figure 6A-B. Fast Fourier-transformed wing beat frequencies of isolated male $(A)$ and female (B) Ae. aegyptiqueenslandensis under laboratory conditions

\subsection{Duet of Male and Female Mosquitoes}

During the duet between the male and the female Ae. aegyptiqueenslandensis, the wing beat frequencies of male mosquitoes ranged from $615 \mathrm{~Hz}$ to $665 \mathrm{~Hz}$ (mean: $638 \pm 89 \mathrm{~Hz}$ ), whereas those of female frequencies ranged from $544 \mathrm{~Hz}$ to $585 \mathrm{~Hz}$ (mean: $558 \pm 38 \mathrm{~Hz}$ ) (Figures 7-10). Student's t-test analysis (Table 1) showed that wing beat frequencies of male mosquitoes differed significantly $(p<0.01)$ during courtship when paired with female mosquitoes in all distances between them. Those of female mosquitoes remained steady when in solo flight and when paired with male mosquitoes in all distances $(p>0.05, d f=3, F=2.36)$. Consistent with Charlwood et al (2002), once a potential mate is located, male mosquitoes orient themselves according to flight tones produced by females.

Table 1. Results of T-test analyses between isolated and paired male and female Ae. aegyptiqueenslandensis

\begin{tabular}{ccc}
\hline $\begin{array}{c}\text { Distance between male } \\
\text { and female }(\mathrm{cm})\end{array}$ & $P$-value (male) & $\begin{array}{c}P \text {-value } \\
\text { (female) }\end{array}$ \\
\hline 1 & 0.002 & 0.599 \\
7 & 0.007 & 0.491 \\
13 & 0.004 & 0.455 \\
19 & 0.003 & 0.299 \\
\hline
\end{tabular}


Courtship duet between the female and the male

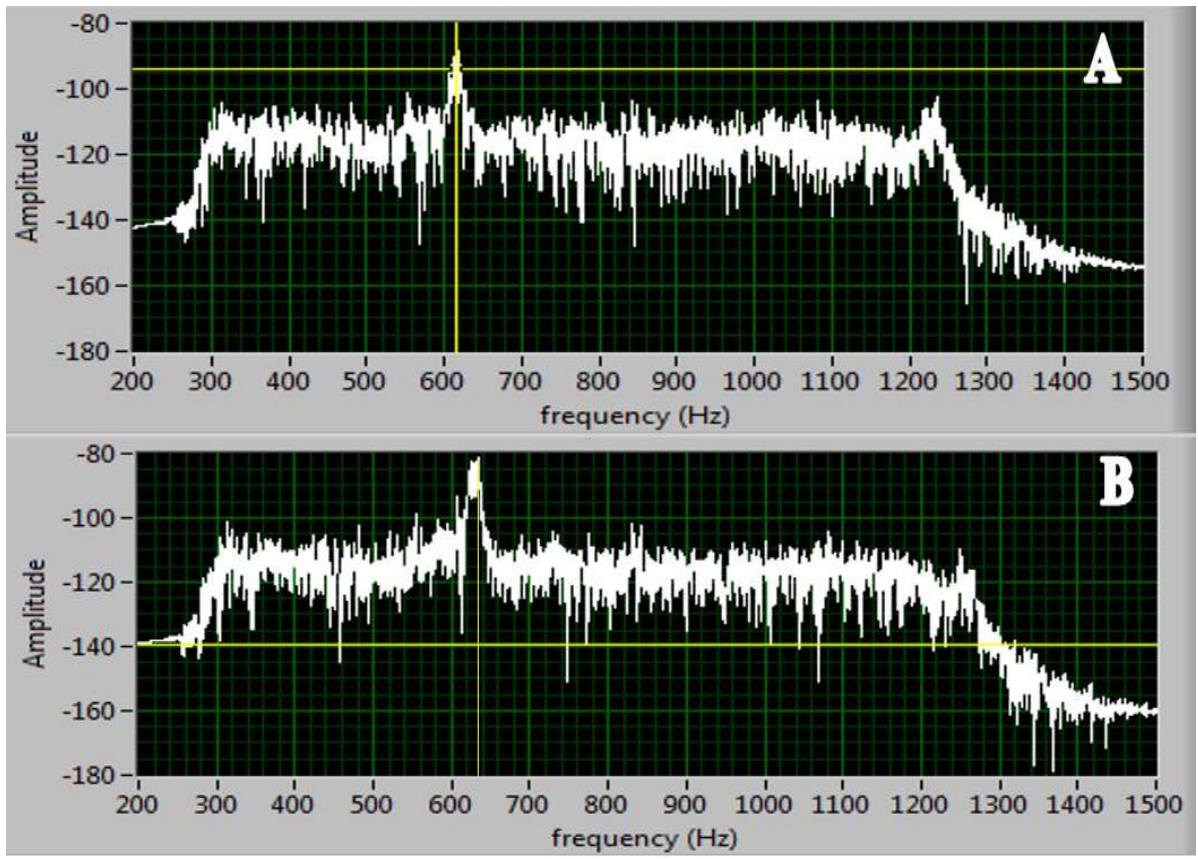

Figure 7A-B. Fast Fourier-transformed wing beat frequencies of male (A) and female (B) Ae. aegypti queenslandensis during courtship at $1-\mathrm{cm}$ distance from each other under laboratory conditions

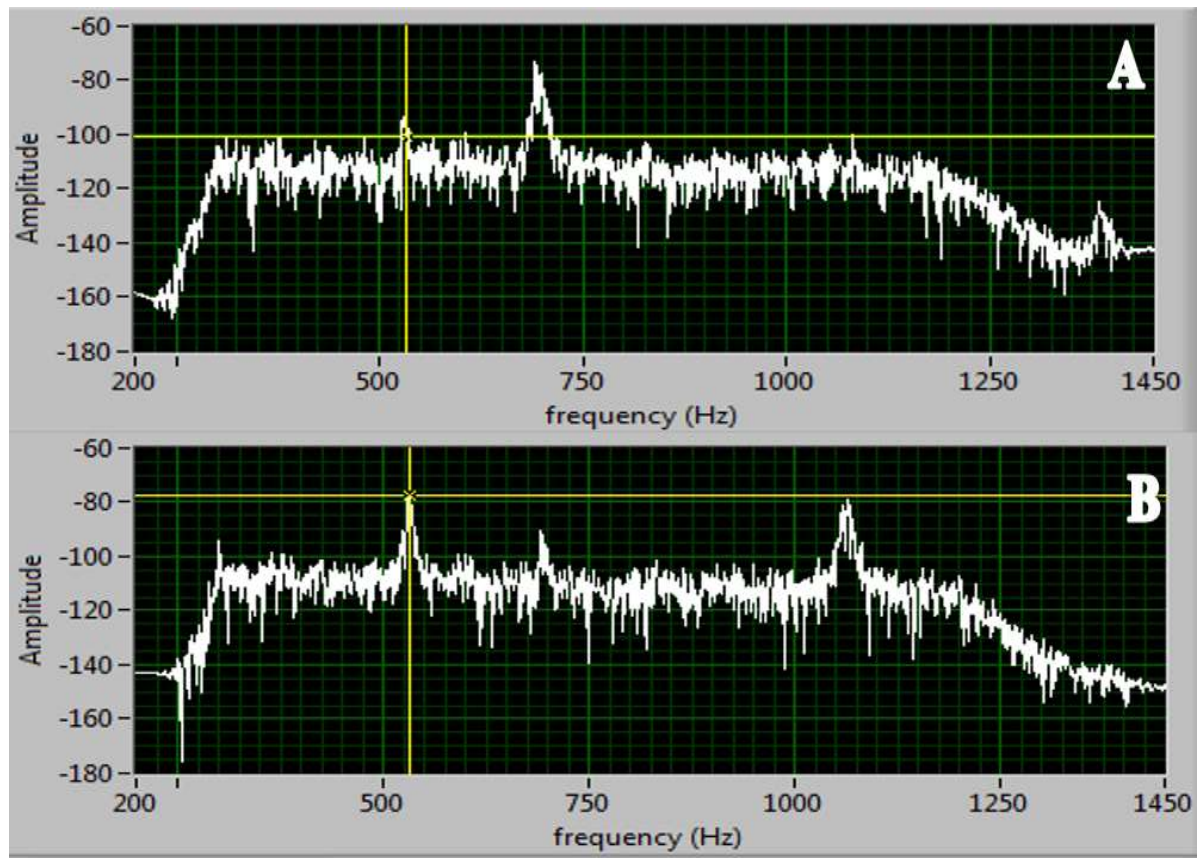

Figure 8A-B. Fast Fourier-transformed wing beat frequencies of male (A) and female (B) Ae. aegypti queenslandensis during courtship at $7-\mathrm{cm}$ distance from each other under laboratory conditions 


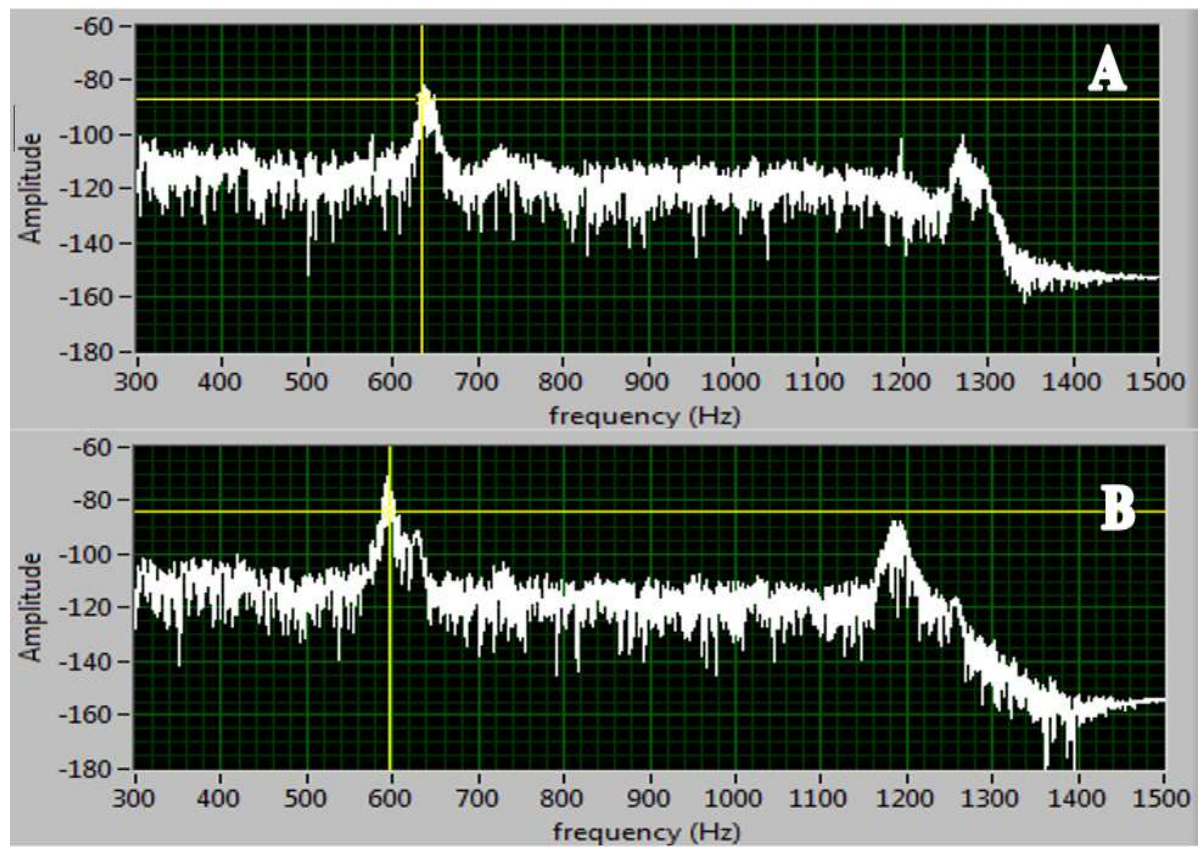

Figure 9A-B. Fast Fourier-transformed wing beat frequencies of male (A) and female (B) Ae. aegyptiqueenslandensis during courtship at $13-\mathrm{cm}$ distance from each other under laboratory conditions

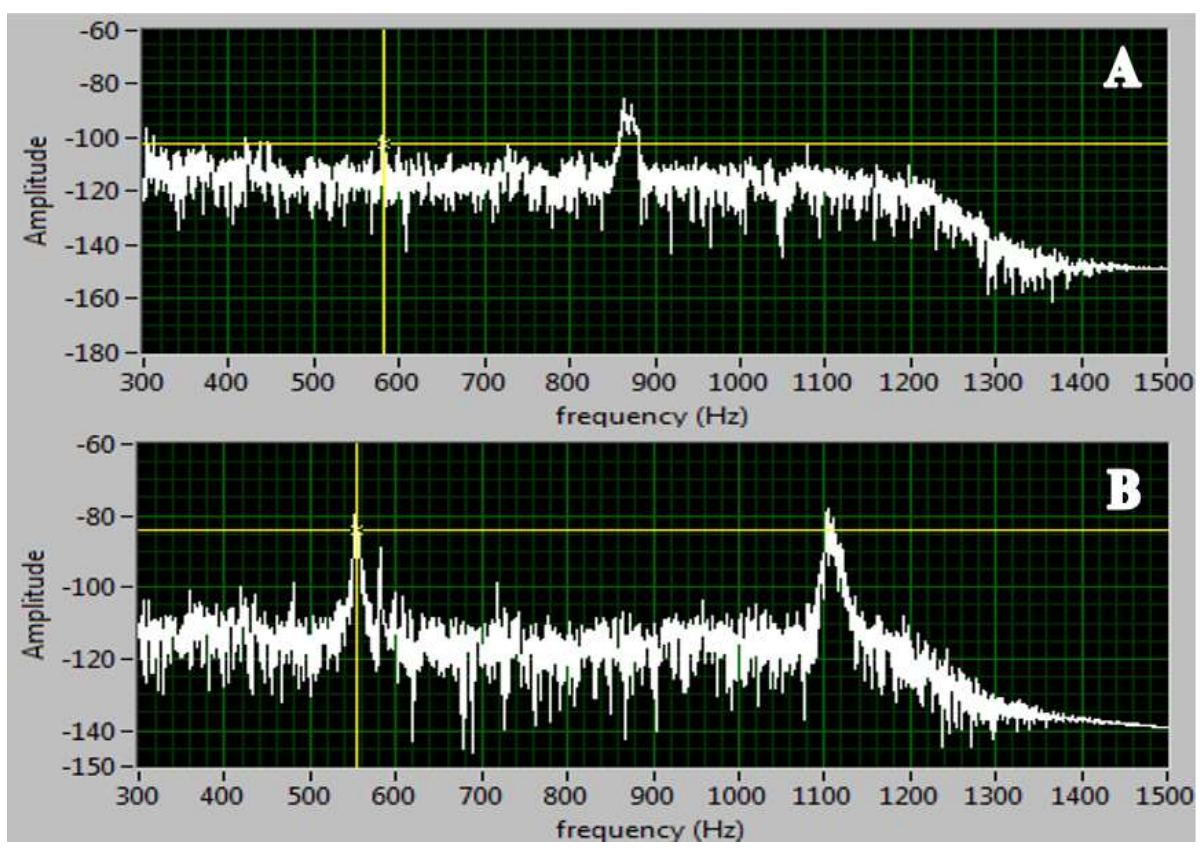

Figure 10A-B. Fast Fourier-transformed wing beat frequencies of male (A) and female (B) Ae. aegyptiqueenslandensis during courtship at $19-\mathrm{cm}$ distance from each other under laboratory conditions 
Courtship duet between the female and the male

All ten pairs of male and female mosquitoes at different distances from each other for three trials demonstrated an apparent effort to converge their wing beats (Figures 11-14) to a common frequency (Table 2). These results were consistent with other mosquitoes, namely, Toxorhynchites brevipalpis (Gibson \& Rusell 2006), Culex quinquefasciatus (Warren et al 2009), Ae. aegypti (Cator et al 2009), and Anopheles gambiae (Pennetier et al 2010). Although the sound generated by the female wings is complex, only the fundamental frequency of their wing beat is essential to attract the males (Wishart \& Riordan 1959); this was confirmed in the present study. In comparison with other insects, which advertise species and sex via time-based pulse patterns (Gerhardt \& Huber 2002), Ae. aegypti queenslandensis can vary only their carrier frequencies of wave signal implying that these mosquitoes could change the wave signals of their wings to convey specific information.

Table 2. Convergence frequencies of the wing beat frequencies of male and female Ae. aegyptiqueenslandensis during courtship under laboratory conditions

\begin{tabular}{ccc}
\hline $\begin{array}{c}\text { Distances between } \\
\text { male and female }(\mathrm{cm})\end{array}$ & $\begin{array}{c}\text { Average } \\
\text { convergence frequency } \\
(\mathrm{Hz})\end{array}$ & $\begin{array}{c}\text { Average } \\
\text { convergence at } \\
\text { harmonics }(\mathrm{Hz})\end{array}$ \\
\hline 1 & $561 \pm 66$ & \\
7 & $575 \pm 21$ & \\
13 & $578 \pm 40$ & $1,022 \pm 6$ \\
19 & $577 \pm 8$ & \\
\hline
\end{tabular}

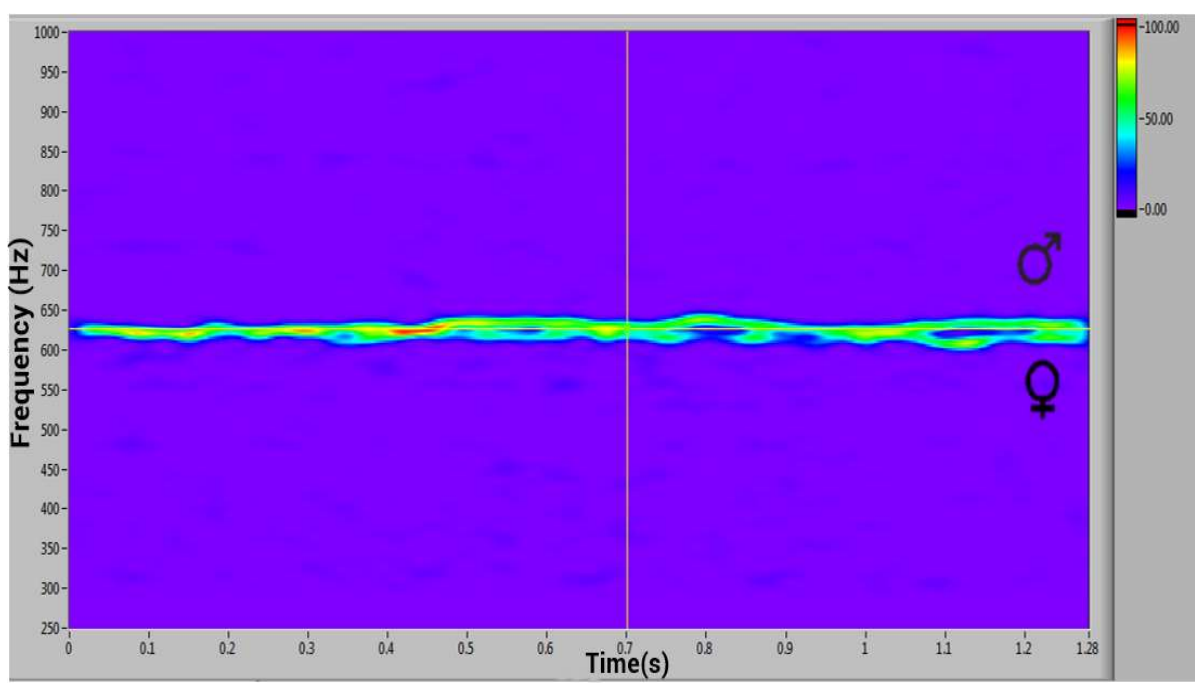

Figure 11. Spectrogram showing convergence frequencies of male and female Ae. aegypti queenslandensis wing beat frequencies at $1-\mathrm{cm}$ distance from each other during courtship under laboratory conditions 
Jamora et al

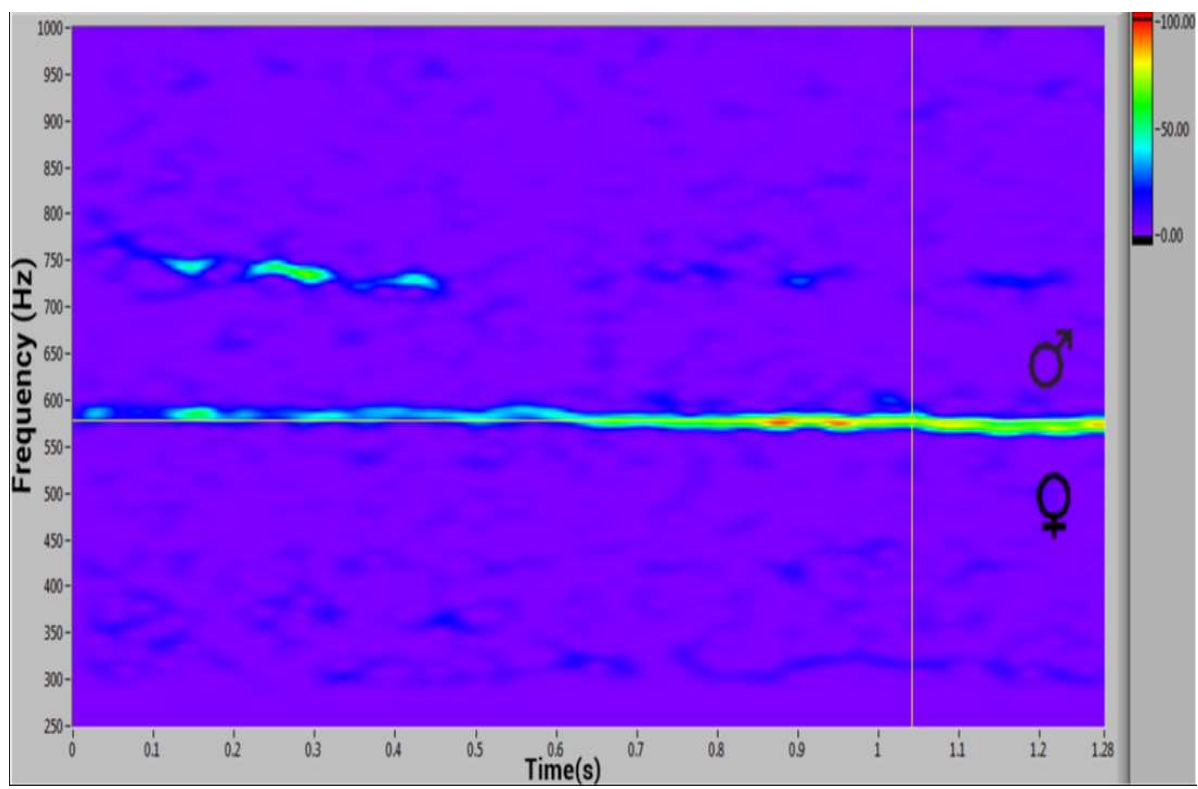

Figure 12. Spectrogram showing convergence frequencies of male and female Ae. aegypti queenslandensis wing beat frequencies at $7-\mathrm{cm}$ distance from each other during courtship under laboratory conditions

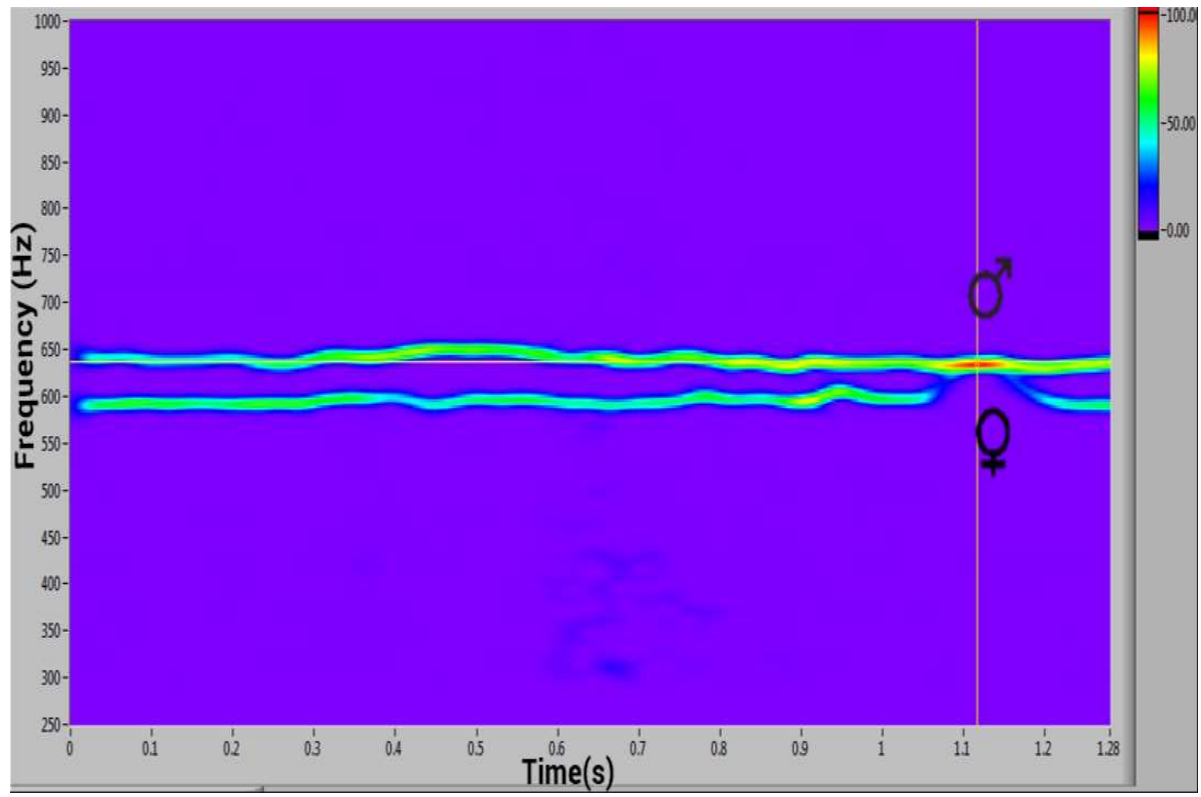

Figure 13. Spectrogram showing convergence frequencies of male and female Ae. aegypti queenslandensis wing beat frequencies at $13-\mathrm{cm}$ distance from each other during courtship under laboratory conditions 
Courtship duet between the female and the male

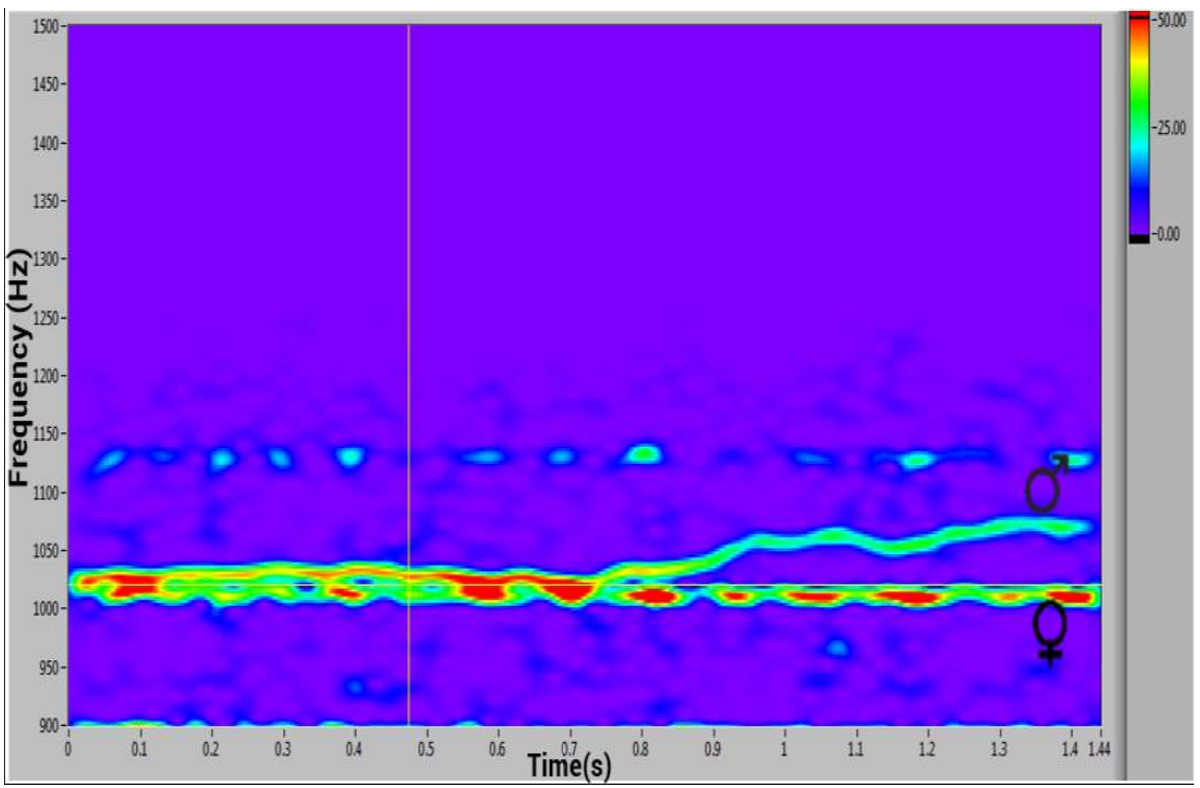

Figure 14. Spectrogram showing convergence frequencies of male and female Ae. aegypti queenslandensis wing beat frequencies at $19-\mathrm{cm}$ distance from each other during courtship under laboratory conditions

\subsection{Harmonicity}

In the current study, all analyses of the wing beat frequencies of Ae. aegypti queenslandensis were restricted to the fundamental frequency, except for the pairs with a 19-cm distance between them (Table 2). This implies that there was convergence of wing beat frequencies at a $19-\mathrm{cm}$ distance between pairs of male and female mosquitoes. Results on the harmonic convergence of mosquito pairs were consistent with the findings of Cator et al (2009). Gibson and Russel (2006) also reported that all pairs of male and female Ae. aegypti converge at their fundamental frequency, within the tuning range of their antennae. Hence, Aldersley et al (2016) noted that harmonic convergence is an active phenomenon and does not occur by chance.

\section{Phase Relationships}

When two mosquitoes are flapping their wings together (converging in the same frequency), trying to converge at a specific frequency, one mosquito is flapping ahead or behind from the other, as reflected by their phase difference. Table 3 shows the phase difference between the two wave signals for each pair of mosquitoes in a duet, with wing beat frequencies in convergence. When this phase difference between the two waves is $0^{\circ}$, these signals are produced simultaneously which imply that both mosquitoes are flapping their wings together at the same time (Crummett \& Western 1994). 
Table 3. Phase difference of the wing beat frequencies of the male and female Ae. aegypti queenslandensis during courtship under laboratory conditions

\begin{tabular}{cc}
\hline $\begin{array}{c}\text { Distances }(\mathrm{cm}) \text { between male and } \\
\text { female }\end{array}$ & $\begin{array}{c}\text { Phase } \\
\text { difference }\left({ }^{\circ}\right)\end{array}$ \\
\hline \hline 1 & $0-75$ \\
13 & $0-55$ \\
19 & $0-75$ \\
\end{tabular}

\section{Spherical Spreading of Male and Female Ae. aegypti queenslandensis}

The mean frequencies of flight tones of male mosquitoes (mean: $987 \pm 18 \mathrm{~Hz}$ ) were higher than those of female mosquitoes $(519 \pm 42 \mathrm{~Hz})$ that were recorded in six major locations of the microphone relative to the tethered mosquitoes (Table 4). Results imply that the sound produced by the flapping of wings of Ae. aegypti queenslandensis spread away spherically, consistent with that of Ae. aegypti (Arthur et al 2014).

The loudest flight tones of male Ae. aegypti queenslandensis were recorded at their back; those of the female, at their left side (Table 4). The quietest flight tones of male mosquitoes were recorded at their right; those of the female, at their upper side (Table 4). Although, these flight tones did not differ significantly $(p>0.05)$ in six locations of the microphones relative to the mosquitoes, this may require further studies on the differences of flight tones at different parts of the male and female mosquitoes. Arthur et al (2014) reported that the loudest flight tones are recorded ahead and behind of $A e$. aegypti, the quietest to their right and left.

Table 4. The mean wing beat frequencies $(\mathrm{Hz})$ of tethered male and female $A$ e. aegypti queenslandensis' flight tone relative to six locations of the microphone

\begin{tabular}{ccc}
\hline $\begin{array}{l}\text { Locations of microphone } \\
\text { relative to mosquitoes }\end{array}$ & Male & Female \\
\hline Back & 1188.18 & 517.36 \\
Down & 949.38 & 526.53 \\
Front & 937.87 & 512.59 \\
Left & 933.43 & 538.10 \\
Right & 931.06 & 526.45 \\
Up & 983.95 & 494.20 \\
\hline Mean \pm SD & $987 \pm 18$ & $519 \pm 42$ \\
\hline
\end{tabular}


Courtship duet between the female and the male

Air, as a fluid medium for sound propagation, has a specific acoustic resistance. To have a good match of the sound source to the medium, the specific acoustic resistance of the source, which depends on its size and configuration (Olson 1957), should match that of the fluid medium (Olson 1957, Bennet-Clark 1995) for effective spreading of sound waves. For some insects, sound spreads as a spherical-wave in the near field or at short ranges from the sound source. In the far field (ie, many wavelengths away), sound propagates as a plane-wave (BennetClark 1998). Sound intensity decreases with both distance and harmonic number.

The current study analyzed several aspects of the flight tone of tethered Ae. aegypti queenslandensis under laboratory conditions in order to better understand the acoustics of these courtship signals. Moreover, both the optimal temperature and $\mathrm{RH}$ for adult mosquitoes' longevity and biting activity are well established, but there were no available data on the optimal conditions for flight activity. Temperature, unlike $\mathrm{RH}$, markedly influences the flight ability of $A e$. aegypti. Rowley and Graham (1967) noted that $\mathrm{RH}(30 \%$ to $90 \%)$ has a very little effect on the flight activity of the virgin female Ae. aegypti, except at $32^{\circ} \mathrm{C}$ with $30 \% \mathrm{RH}$, in which flight depression can occur. If temperature conditions are suitable, mosquitoes may fly at any $\mathrm{RH}$, therefore, their performance at any given temperature is independent of the $\mathrm{RH}$ (Rowley \& Graham 1967).

Since the early 1900s, acoustic recording and playback technologies have already been employed for both insect detection and monitoring (Mankin et al 2011). Acoustic devices attract and trap insects (Walker 1988, Walker 1996), manipulate their behavior (Gwynne 1995), and interrupt intraspecific communication (Samarra et al 2009). These devices do not just capture, sterilize, or kill but also collect the live specimens for biological studies (Fowler 1988, Campbell \& Shipp 1974) and control programs (Frank 1994, Frank \& Walker 2006), and monitor insect diversity (Riede 1998, Chesmore \& Ohya 2004), population levels (Forrest 1988, Mankin 1994, Raman et al 2007), and their geographic distributions (Cooley et al 2011).

Several studies attempted to test the effectiveness of sonic pest devices but most such as those for ants (Huang et al 2002), cockroaches (Schreck et al 1984, Gold et al 1984, Koehler et al 1986), and bed bugs (Yturralde \& Hofstetter 2012) were ineffective. Interestingly, some devices are able to attract, repel, and increase Ae. aegypti's bite rate by as much as 50\% (Andrade \& Cabrini 2010). Greenlee (1970) described that commercial mosquito "repellers" are sine waves (Kutz 1974, Singleton 1977) or fundamental frequencies.

A few studies (Roth 1948, Belton \& Costello 1979) reported that a female mosquito is repelled by the same sound frequency that attracts the male. The sound that attracts the male mosquito is generated by the female wings. In the present study, the fundamental frequency of the female, at which the male Ae. aegypti queenslandensis converged, was at $544 \mathrm{~Hz}$ to $585 \mathrm{~Hz}$ (mean: $558 \pm 38 \mathrm{~Hz}$ ). For this type of mosquito control, the focus is not only on females but also males because they play a role in courtship. Thus, developing an acoustic device that produces within the range of frequencies can disrupt the wing beat frequencies of both sexes from converging and can prevent their courtship and subsequently their mating. This device can help in the control of Ae. aegypti queenslandensis without using harmful chemicals. Although there are devices that produce such frequencies and have been tested on other insects, these frequencies acted only as 
attractants rather than repellants on Ae. aegypti or Culex pipiens (Greenlee 1970). Construction of these devices requires thorough research considering temperature and humidity of the environment as well.

\section{CONCLUSION AND RECOMMENDATIONS}

In conclusion, the male Ae. aegypti queenslandensis' wing beat frequency converged with the female's frequency at their fundamental frequency, with a range of phase difference for each of the distances tested between these mosquito pairs. Sound produced by the flapping of wings, spread away from the mosquito spherically, which is true for both the type form (Mattingly 1957) and Ae. aegypti queenslandensis.

For further studies, we recommend to determine the following: (1) the wing beat frequency of Ae. aegypti queenslandensis and Ae. albopictus in free flight, (2) differences of flight tones between male and female dengue mosquitoes, (3) if different levels of temperature and relative humidity affect the mosquitoes' flight tones, and (4) if different wing sizes affect the mosquito's wing beat frequency.

\section{ACKNOWLEDGMENT}

We would like to thank Renante Violanda for his help in LabVIEW programming.

\section{REFERENCES}

Aldersley A, Champneys A, Homer M \& Robert D. 2016. Quantitative analysis of harmonic convergence in mosquito auditory interactions. Journal of the Royal Society Interface, 13:20151007

Andrade CF and Cabrini I. 2010. Electronic mosquito repellers induce increased biting rates in Aedes aegypti mosquitoes (Diptera: Culicidae). Journal of VectorEcology, 35(1):75-78

Arthur BJ, Sunayama-Morita T, Coen P, Murthy M \& Stern DL. 2013. Multi-channel acoustic recording and automated analysis of Drosophila courtship songs. BMC Biology, 11:11

Arthur BJ, Wyttenbach RA, Harrington LC \& Hoy RR. 2010. Neural responses to oneand two-tone stimuli in the hearing organ of the dengue vector mosquito. Journal of Experimental Biology, 213:1376-1385

Arthur BJ, Emr K, Wyttenbach RA \& Hoy RR. 2014. Mosquito (Aedes aegypti) flight tones: Frequency, harmonicity, spherical spreading, and phase relationships. The Journal of the Acoustical Society of America, 135(2):933-941

Belton P. 1974. An analysis of direction finding in male mosquitoes. In Experimental Analysis of Insect Behavior. (pp139-148)

Belton P and Costello RA. 1979. Flight sounds of the females of some mosquitoes of Western Canada. Entomology Experiment Application, 26:105-114

Benelli and Mehlhorn. 2016. Declining malaria, rising of dengue and Zika virus: insights for mosquito vector control. Parasitology Research, 115(5):1747-1754

Bennet-Clark HC. 1995. Insect sound propagation: transduction mechanisms and impedance matching. In Biological fluid dynamics (ed. C.P. Ellington and T.J. Pedley). Symposium of the Society of Experimental Biology, 49:199-218 
Courtship duet between the female and the male

Bennet-Clark HC. 1998. Size and scale effects as constraints in insect sound communication. Philosophical Transactions of the Royal Society of London, Series B, 353:407-419

Brillinger DR. 1965. An introduction to polyspectra. Annals of Mathematical Statistics, 36:1351-1374

Brown JC and Puckette MS. 1993. A high resolution fundamental frequency determination based on phase changes of the Fourier transform. Journal of the Acoustical Society of America, 94:662-667

Campbell DJ and Shipp E. 1974. Spectral analysis of cyclic behaviour with examples from the field cricket Teleogryllus commodus (walk.). Animal Behaviour, 22:862-875

Capeding MR, Ngoc HT, Hadinegoro SRS, Ismail HM, Chotpitayasunondh T, Chua MN, Luong CQ, Rusmil K, Wirawan DN, Nallusamy R, Pitisuttithum P, Thisyakorn U YOON I-K, Vliet D, Langevin E, Laot T, Hutagalung Y, Frago C, Boaz M, Wartel TA, Tornieporth NG, Saville M, Bouckenooghe A \& CYD14 STUDY GROUP. 2014. Clinical efficacy and safety of a novel tetravalent dengue vaccine in healthy children in Asia: a phase 3, randomized, observer-masked, placebo-controlled trial. Elsevier, 9951:1358-1365

Cator LJ, Arthur BJ, Harrington L \& Hoy RR. 2009. Harmonic convergence in the love songs of the dengue vector mosquito. Science, 323:1077-1079

Cator LJ, Arthur BJ, Ponlawat A \& Harrington LC. 2011. Behavioral observations and sound recordings of free-flight mating swarms of Ae. aegypti (Diptera: Culicidae) in Thailand. Journal of Medical Entomology, 48(4):941-946

Charlwood JD and Jones MR. 1979. Mating behaviour in the mosquito Anopheles gambiae. Physiology Entomology, 4(2):111-120

Charlwood JD, Pinto J, Sousa CA, Madsen H, Ferreira C \& do Rosario VE. 2002. The swarming and mating behaviour of Anopheles gambiae s.s. (Diptera:Culicidae) from São Tomé Island. Journal of Vector Ecology, 27(2):178-183

Charpentier FJ. 1986. Pitch detection using the short-term phase spectrum. Proceedings of the International Conference on Acoustics, Speech, and Signal Processing (IEEE), New York. (pp113-116)

Chesmore ED and Ohya E. 2004. Automated identification of fieldrecorded songs of four British grasshoppers using bioacoustic signal recognition. Bulletin of Entomological Research, 94(4):319-330

Clements AN. 1999. The antennae and hearing. In The Biology of Mosquitoes. CABI Publishing, New York

Clemons A, Mori A, Haugen M, Severson D \& Duman-Scheel M. 2010. Aedes aegypti Culturing and Egg Collection. Cold Spring Harbor Protocols

Cooley JR, Kritsky G, Edwards MJ, Zyla JD, Marshall DC \& Hill KBR. 2011. Periodical cicadas (Magicicada spp.): a GIS-based map of broods XIV in 2008 and 'XV' in 2009. American Entomologist, 57(3):144-151

Crummett WP and Western AB. 1994. University Physics: Models and Applications. Oscillations, William C. Brown Publishing, USA

Cebu CHO (City Health Office). 2016. Dengue Surveillance Report 2016. Cebu City, Philippines

DOH (Department of Health). 2017. DOH puts immunization after new findings from Sanofi-Pasteur. DOH Office of the Secretary, Sta. Cruz, Manila, Philippines

Edillo FE, Sarcos JR \& Sayson SL. 2015. Natural vertical transmission of dengue viruses in Aedes aegypti in selected sites in Cebu City, Philippines. Journal of Vector Ecology, 40(2):282-291

Edillo FE, Roble ND \& Otero ND 2nd. 2012. The key breeding sites by pupal survey for dengue mosquito vectors, Aedes aegypti (Linnaeus) and Aedes 
albopictus (Skuse), in Guba, Cebu City, Philippines. Southeast Asian Journal of Tropical Medicine and Public Health, 43(6):1365-74

Forrest TG. 1988. Using insect sounds to estimate and monitor their populations. Florida Entomologist, 71(4):416-426

Fowler HG. 1988. Traps for collecting live Euphasiopteryx depleta (Diptera: Tachinidae) at a sound source. Florida Entomologist, 71(4): 654-656

Frank JH. 1994. Biological control of pest mole crickets. Pest management in the subtropics: biological control - a Florida perspective. Intercept Limited, Andover, UK. (pp343-352)

Frank JH and Walker TJ. 2006. Permanent control of pest mole crickets (Orthoptera: Gryllotalpidae: Scapteriscus). American Entomologist, 52(3):138-144

Gerhard HC and Huber F. 2002. Acoustic communication in insects and anurans: common problems and diverse solutions. University of Chicago Press, Chicago. (p531)

Gibson $\mathrm{G}$ and Russell IJ. 2006. Flying in tune: sexual recognition in mosquitoes. Current Biology, 16(13):1311-1316

Gold RE, Decker TN \& Vance AD. 1984. Acoustical characterization and efficacy evaluation of ultrasonic pest control devices marketed for control of German cockroaches (Orthoptera: Blattellidae). Journal of Economic Entomology, 77(6):1507-1512

Göpfert MC, Briegel H \& Robert D. 1999. Mosquito hearing: sound induced antennal vibrations in male and female Aedes aegypti. Journal of Experimental Biology, 202:2727-2738

Greenlee LE. 1970. Build the bug shoo. Popular Electronics (pp27-30)

Gwynne DT. 1995. Phylogeny of the Ensifera (Orthoptera): a hypothesis supporting multiple origins of acoustical signaling, complex spermatophores and maternal care in crickets, katydids, and weta. Journal of Orthoptera Research, 4(4):203-218

Huang F, Subramanyam B \& Clark J. 2002. Laboratory and field trials with commercial ultrasonic devices against three ant species (Hymenoptera: Formicidae). Journal of Agricultural and Urban Entomology, 19(1):25-28

Kalra NL, Wattal BL \& Raghavan NGS. 1985. Distribution pattern of Aedes (Stegomyia) aegypti in India: some ecological considerations. Bulletin of the Catalysis Society of India, 5:307-334

Kim YC and Powers EJ. 1979. Digital bispectral analysis and its applications to nonlinear wave interactions. IEEE, Transactions on Plasma Science, 7(2):120-131

Koehler PG, Patterson RS \& Webb JC. 1986. Efficacy of ultrasound for German cockroach (Orthoptera: Blattellidae) and oriental rat flea (Siphonoptera: Pulicidae) control. Journal of Economic Entomology, 79(4):1027-1031

Kutz FW. 1974. Evaluations of an electronic mosquito repelling device. Mosquito News, 34(4):369-375

Leal WS. 2014. The enigmatic reception of DEET - the gold standard of insect repellants. Current Opinion in Insect Science, 6:93-98

Mankin RW. 1994. Acoustical detection of Aedes taeniorhynchus swarms and emergence exoduses in remote salt marshes. Journal of the American Mosquito Control Association, 10:302-308

Mankin RW, Hagstrum DW, Smith MT, Roda AL \& Kairo MTK. 2011. Perspective and promise: a century of insect acoustic detection and monitoring. American Entomologist, 57(1):30-44

Mattingly PF. 1957. Genetical aspects of the Aedes aegypti problem. I: Taxonomy and bionomics. Annals of Tropical Medicine and Parasitology, 51(4):392-408 
Courtship duet between the female and the male

Mendel JM. 1991. Tutorial on higher-order statistics (spectra) in signal processing and system theory: theoretical results and some applications. Proceedings of the International Conference on Acoustics, Speech, and Signal Processing. Proceedings of the IEEE, 49(3):278-305

Nikbakhtzadeh M, Buss G \& Leal W. 2016. Toxic effect of blood feeding in male mosquitoes. Frontiers in Physiology, 7:4

Olson H.F. 1957. Acoustical engineering. Princeton, Van Nostrand

Pennetier C, Warren B, Dabiré KR, Russell IJ \& Gibson G. 2010. 'Singing on the wing' as a mechanism for species recognition in the malarial mosquito Anopheles gambiae. Current Biology, 20(3):131-136

Raman DR, Gerhard RR \& Wilkerson JB. 2007. Detecting insect flight sounds in the field: implications for acoustical counting of mosquitoes. Transactions of the American Society of Agricultural and Biological Engineers, 50(4):1481-1485

Rasic G, Filipovic I, Callahan A, Stanford D, Chan A, Lamphua SG, Tan CH \& Hoffmann AA. 2016. The queenslandensis and the type form of the dengue fever mosquito (Aedes aegypti L.) are genomically indistinguishable. PLoS Neglected Tropical Diseases, 10(11): e0005096

Riede K. 1998. Acoustic monitoring of Orthoptera and its potential for conservation. Journal of Insect Conservation, 2(3):217-223

Roth LM. 1948. A study of mosquito behavior. An experimental laboratory study of the sexual behavior of Aedes aegypti (Linnaeus). American Midland Naturalist Journal, 40(2):265- 352

Rowley W and Graham C. 1967. The effect of temperature and relative humidity on the flight performance of female Aedes aegypti. Journal of Insect Physiology, 14(9):1251-1257

Samarra FIP, Klappert K, Brumm H \& Miller PJO. 2009. Background noise constrains communication: acoustic masking of courtship song in the fruit fly Drosophila montana behaviour. Behaviour, 146(12):1635-1648

Schreck CF, Webb JC \& Burden GS. 1984. Ultrasonic devices: evaluation of repellency to cockroaches and mosquitoes and measurement of sound output. Journal of Environmental Science and Health Part A, 19(5):521-531

Shepard DS, Undurraga EA \& Halasa YA. 2013. Economic and disease burden of dengue in Southeast Asia. PLoS Neglected Tropical Diseases, 7(2):e2055

Singleton RE. 1977. Evaluation of two mosquito-repelling devices. Mosquito News, 37:195-199

Sotavalta O. 1947. The flight-tone (wing-stroke frequency) of insects. Acta Entomology Fennica, 4:117

Tischner H. 1953.U" ber den Geho" rsinn von Stechmu" cken. Acustica, 3:335-343

Tischner $\mathrm{H}$ and Schieff A. 1855. Fluggera" usch und Schallwahrnehmung bei Aedes aegypti L. (Culicidae). Zoologischer Anzeiger, 18:453-460

Thungrungkiat S, Wasinpiyamongkol L, Maneekan P, Prummongkol S \& Samung Y. 2012. Natural transovarial dengue virus infection rate in both sexes of dark and pale forms of Aedes aegypti from an urban area in Bangkok, Thailand. Southeast Asian Journal of Tropical Medicine Public Health, 43(5):1146-1152

Walker TJ. 1988. Acoustic traps for agriculturally important insects. Florida Entomologist, 71(4):484-492

Walker TJ. 1996. Acoustic methods of monitoring and manipulating insect pests and their natural enemies. In: pest management in the subtropics: integrated pest management - a Florida perspective. Intercept Limited, Andover, Hants, UK. (pp245-257) 
Warren B, Gibson G \& Russell IJ. 2009. Sex recognition through midflight mating duets in Culex mosquitoes is mediated by acoustic distortion. Current Biology, 19(6):485-491

Webb JC, Sharp JL, Chambers DL \& Benner JC. 1976. Acoustical properties of the flight activities of the Caribbean fruit-fly. Journal of Experimental Biology, 64:761-772

World Health Organization (WHO). 2016. Zika Fact Sheet (March 15, 2016) Available at:http://www.who.int/mediacentre/factsheets/zika/en/.

World Health Organization: Western Pacific Regional Office (WHO- WPRO). 2013. Dengue Situation Update (December 24, 2013) Available at: http://www.wpro.who.int/emerging_diseases/Dengue.Biweekly

Williams CM and Galambos R. 1950. Oscillographic and stroboscopic analysis of the flight sounds of Drosophila. Biology Bullletin, 99(2):300-307

Wishart $\mathrm{G}$ and Riordan DF. 1959. Flight responses to various sounds by adult males of Aedes aegypti (L.) (Diptera: Culicidae). The Canadian Entomologist, 91(3):181-191

Wishart G, Sickle GR \& Riordan DF. 1962. Orientation of the males of Aedes aegypti (L) (Diptera: Culicidae) to sound. Canadian Entomologist Journal, 94(6):613-626

Yturralde KM and Hofstetter RW. 2012. Efficacy of commercially available ultrasonic pest repellent devices to affect behavior of bed bugs (Hemiptera: Cimicidae). Journal of Economic Entomology, 105(6):21072114 